\title{
Seed size and its influence on germination, seedling growth and biomass in Saraca asoca (Roxb). De Wilde, critically endangered tree species of Western ghats, India
}

\author{
A. B. Mirgal ${ }^{1}$, Rajesh P. Gunaga ${ }^{2 *}$, and C.B. Salunkhe ${ }^{3}$ \\ ${ }^{1}$ College of Forestry, Dr. B.S. Konkan Krishi Vidyapeeth, Dapoli-415712 (Maharashtra), INDIA \\ ${ }^{2}$ College of Forestry, ACHF, Navsari Agricultural University, Navsari-396450 (Gujarat), INDIA \\ ${ }^{3}$ Krishna Mahavidyalaya, Rethare Bk., Karad-415 108 (Maharashtra), INDIA \\ *Corresponding author. E-mail: rpgunaga@gmail.com
}

Received: March 08, 2015; Revised received: June 04, 2016; Accepted: August 18, 2016

\begin{abstract}
Saraca asoca (Roxb). De Wilde is one of the high traded medicinal plant species of India. There is a huge demand for bark of this species both in domestic and international markets. There is a demand for quality planting materials for large scale plantation. Forest department and farmers have already initiated captive plantation of this species. Several factors affect the seedling quality in nursery. Seed grading is one among them. The present study aims at understand the influence of seed size on seed germination and seedling vigour in $S$. asoca. Association study showed that seed length was positively correlated with seed weight $(r=0.887)$, seed width $(r=0.697)$ and thickness $(r=0.621)$. Therefore, seed length was used to categorize seedlot into small $(<30.0 \mathrm{~mm})$, medium $(30.1-40.0$ $\mathrm{mm}$ ) and large (> $40.1 \mathrm{~mm}$ ) seeds. Result showed that larger seeds produced maximum germination $(86.7 \%)$ as compared to smaller seeds (45.0\%). Moreover, larger seeds attained higher collar diameter (3.34 mm) and dry biomass viz., leaf biomass $(0.91 \mathrm{~g})$, shoot biomass $(0.31 \mathrm{~g})$, root biomass $(0.95 \mathrm{~g})$ and entire seedling biomass $(2.17 \mathrm{~g})$ as compared to smaller seeds. Seedlings raised from medium seeds were at par with larger seeds in most of the traits. Therefore, it is suggested to use seedlot having $>30 \mathrm{~mm}$ length, preferably larger seeds $(>40 \mathrm{~mm})$ in the nursery for better establishment of quality seedlings.
\end{abstract}

Keywords: Conservation, Germination, Saraca asoca, Seed size, Seedling vigour

\section{INTRODUCTION}

Saraca asoca (Roxb). De Wilde (Family- Legumonosae; sub-family- Ceasalpiniodeae) is one of the commercial medicinal tree species of India. It is an understory tree distributed in tropical evergreen forests. Species is well recognized as most sacred trees of Hindus and Buddhists. Species is recognised as one of the high traded medicinal plant species of tropical forests of India with annual consumption of 2041 metric tonnes (Ved and Goraya, 2007), where bark has got high commercial value which contains ketosterol, tannin, Epicatechin, Procyanidin $\mathrm{B}_{2}, 11^{\prime}$ deoxyprocyanidin $\mathrm{B}_{2}$, polymeric procyanidins and Saracin (CSIR, 1952; Middlekoop, 1985; Ray et al., 1995). In Ayurvedic medicine, bark of Saraca asoca is mainly used in women disorders. Due to all these medicinal properties, species is in huge demand both in domestic and international markets. Presently, raw material is mainly procured from natural forests. In India, efforts to initiate conservation and domestication of species have been attempted (Haridasan et al., 2003; Walad, 2008). In order to conserve and commercialize the species, information on seed traits, germination attributes and seedling vigour are essential. Furthermore, quality seedling production depends upon several factors, where seed size is one among them that affects seed germination and seedling vigour. There was a great variation in seed size from collected seedlots. Therefore, the present study was undertaken with the following objectives: a) to understand the pattern of seed characteristics and b) to study the influence of different seed size classes on seed germination and seedling vigour in $S$. asoca.

\section{MATERIALS AND METHODS}

The present study was undertaken at College of Forestry, Dapoli, Maharashtra. Matured pods were collected from different trees in a natural forest of Phookeri near Banda of Dodamarg Forest Division of Maharashtra during June, 2012. Geo-coordinate of study area is $15^{\circ} 50^{\prime} 41.1^{\prime \prime} \mathrm{N}$ and $73^{\circ} 57^{\prime} 56.7^{\prime \prime} \mathrm{E}$. Pods were collected from this forest and they were air dried for five days to split open and then seeds were extracted. Seedlot collected was showed lot of variation for seed size. Therefore, seedlots were categorized into three different seed size classes viz., small $(<30.0 \mathrm{~mm})$, medium $(30.1-40.0 \mathrm{~mm})$ and large $(>40.1 \mathrm{~mm})$ based on 
seed length to understand seed size on seed germination and seedling vigour. For each size class, 75 seeds were used for germination experiments. Seeds of different size classes were sown on nursery bed with three replications following Completely Randomized Design (CRD) under mist chamber. Methodology has been developed by following Gunaga (2011), where he studied the influence of seed size on seed germination and seedling vigour in Calophyllum inophyllum. Daily observation on seed germination was recorded up to 90 days from the date of sowing. Later, 20 seedlings of three months old from each size classes were uprooted and seedling growth attributes such plant height, number of leaves, collar diameter, root length, fresh weight and dry weight were recorded. Data were subjected to statistical analysis using $\mathrm{mStat}-\mathrm{C}$ package and analysis of variance was constructed following Gomez and Gomez (1984).

\section{RESULTS AND DISCUSSION}

Variation in seed size in a seedlot collected from natural population was recorded and it ranged from 21.83 to $48.58 \mathrm{~cm}$. The frequency of occurrence of seeds into different seed size classes is depicted in fig. 1. Considering seed thickness, majority of seeds belonged to 10$20 \mathrm{~mm}$ thickness. In case of seed length, maximum seeds belonged to the class $35-45 \mathrm{~cm}$. However, in seed weight, majority of seeds showed 12-16 g weight with seed width of $20-30 \mathrm{~mm}$ (Fig. 1). In this study, relationship among seed traits was tested by a simple Pearson's correlation, where seed length (considered as unit of seed size) showed strong positive association
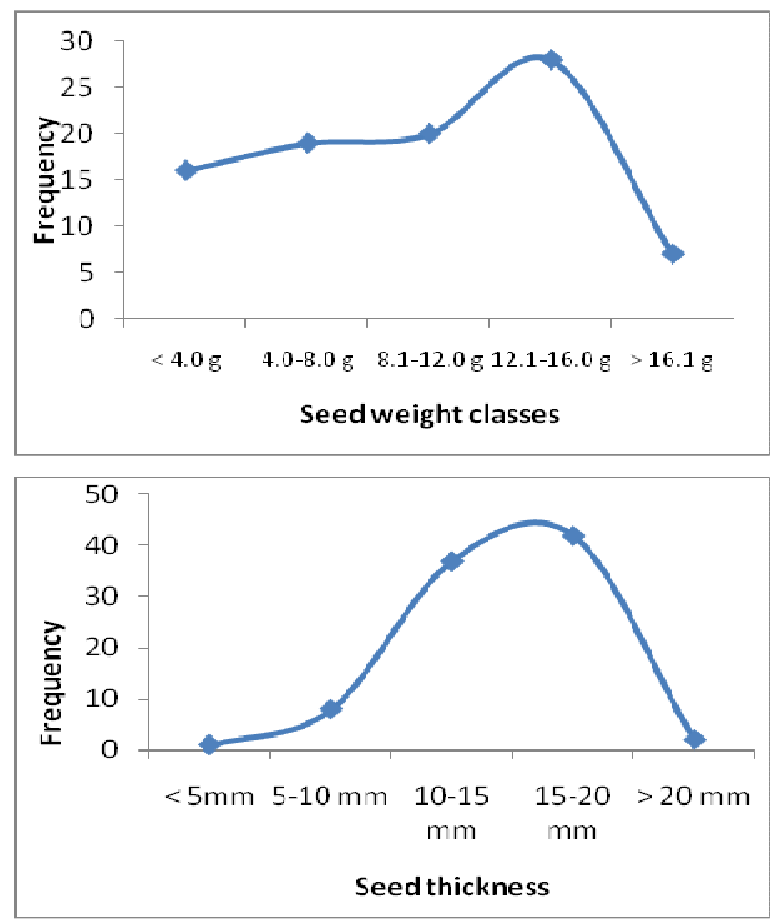

with seed weight $(\mathrm{r}=0.887 ; \mathrm{P}=0.01)$, seed width $(\mathrm{r}=0.697 ; \mathrm{P}=0.01)$ and thickness $(\mathrm{r}=0.621 ; \mathrm{P}=0.01)$.

There was a significant variation among three seed size classes for seed germination and early seedling vigour (Fig. 2; Table 1). Germination started from 25 days after sowing (DAS) and continued up to 80 DAS. Germination pattern in three seed size classes was recorded periodically and is presented in Fig. 2. Final germination count was recorded on 80 DAS, where bigger seeds resulted in quick and highest seed germination of $86.7 \%$, followed by medium sized seeds $(83.30 \%)$. However, smaller seeds resulted in 45.0 per cent germination (Fig. 2). Seedling growth characteristics such as shoot height, collar diameter, number of leaves and root length were recorded among three seed size classes. Shoot height, number of leaves and root length did not show significant among three size classes; however, collar diameter, fresh weight and dry weight of leaves, shoot, root and entire plant showed significant variation (Table 1 and 2). Based on mean values, bigger sized seeds showed higher shoot height $(15 \mathrm{~cm})$, collar diameter $(3.34 \mathrm{~mm})$ and root length $(23.27 \mathrm{~cm})$ than those from medium and smaller seeds. Considering biomass, seed size also positively influenced on fresh and dry biomass of seedlings where dry biomass of leaf $(0.91 \mathrm{~g})$, shoot $(0.31 \mathrm{~g})$, root $(0.95 \mathrm{~g})$ and entire seedling $(2.17 \mathrm{~g})$ was found to be highest in seedlings raised from bigger seeds, which was almost three times more than those seedlings raised from smaller seeds (Table 2).

Quality seedling production is main objective of forest nursery that depends upon several factors such as seed
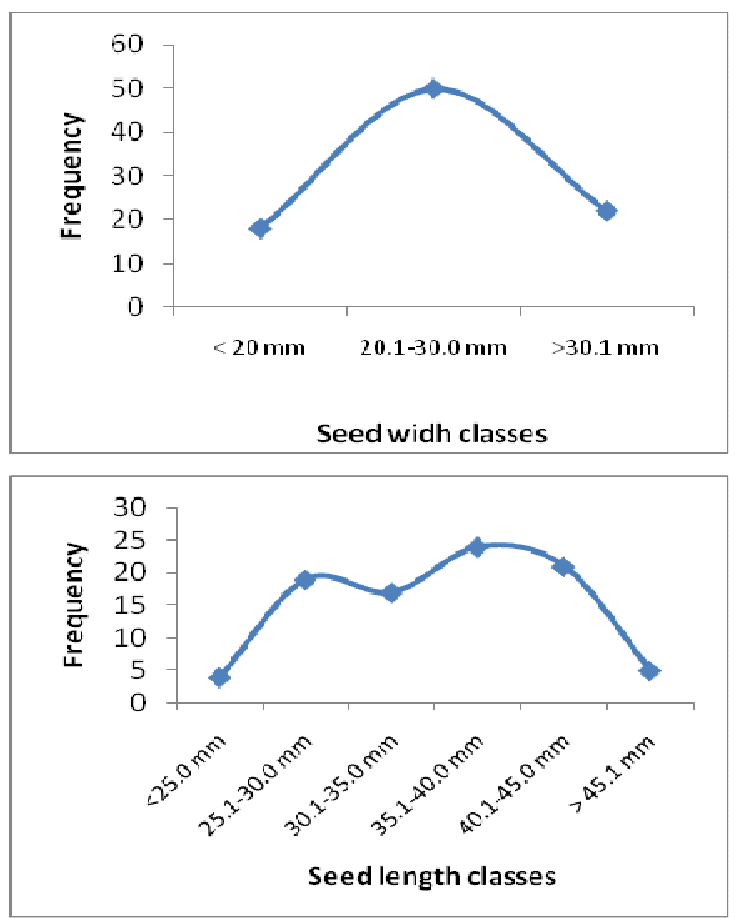

Fig. 1. Distribution of seeds into different classes of seed traits in S. asoca. 


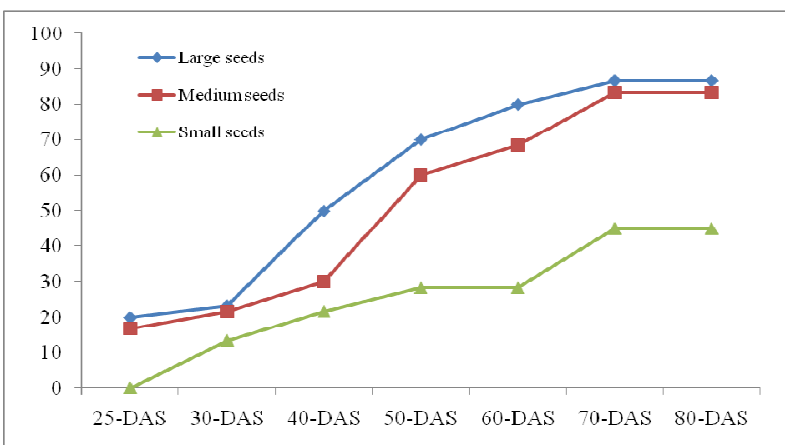

Fig. 2. Influence of seed size on seed germination in $S$. asoca.
Table 1. Effect of seed size on seedling growth in $S$. asoca [N=20].

\begin{tabular}{ccccc}
\hline $\begin{array}{c}\text { Seed } \\
\text { size } \\
\text { Classes }\end{array}$ & $\begin{array}{c}\text { Shoot } \\
\text { length } \\
\text { (cm) }\end{array}$ & $\begin{array}{c}\text { Root } \\
\text { length } \\
(\mathbf{c m})\end{array}$ & $\begin{array}{c}\text { Collar } \\
\text { diameter } \\
(\mathbf{m m})\end{array}$ & $\begin{array}{c}\text { No. of } \\
\text { Leaves } \\
\text { per plant }\end{array}$ \\
\hline Large & 15.00 & 23.27 & 3.34 & 7.50 \\
Medium & 15.92 & 22.28 & 3.02 & 5.40 \\
Small & 12.20 & 21.76 & 2.48 & 4.80 \\
Mean & 14.37 & 22.44 & 2.95 & 5.90 \\
CD @ & & & & \\
$\mathbf{5 \%} \mathbf{P}$ & $\mathrm{NS}$ & $\mathrm{NS}$ & 0.45 & $\mathrm{NS}$ \\
\hline
\end{tabular}

$\mathrm{CD}=$ Critical Difference; $\mathrm{P}=$ Probability; $\mathrm{NS}=$ Nonsignificant

Table 2. Effect of seed size on fresh and dry biomass of seedlings in $S$. asoca [N=20].

\begin{tabular}{cccccccccc}
\hline \multirow{2}{*}{ Seed size Classes } & \multicolumn{4}{c}{ Fresh weight $(\mathbf{g})$} & \multicolumn{7}{c}{ Dry weight $(\mathbf{g})$} & $\begin{array}{c}\text { Moisture } \\
\text { content (\%) }\end{array}$ \\
\cline { 2 - 9 } & Shoot & Leaf & Root & Total & Shoot & Leaf & Root & Total & 65.46 \\
Large & 0.99 & 2.64 & 2.67 & 6.30 & 0.31 & 0.91 & 0.95 & 2.17 & 66.84 \\
Medium & 0.75 & 2.20 & 2.28 & 5.23 & 0.25 & 0.65 & 0.82 & 1.72 & 68.40 \\
Small & 0.44 & 1.05 & 0.81 & 2.30 & 0.14 & 0.34 & 0.28 & 0.76 & 66.90 \\
Mean & 0.73 & 1.96 & 1.92 & 4.61 & 0.23 & 0.63 & 0.68 & 1.55 & NS \\
CD @ 5\% P & 0.26 & 1.01 & 0.62 & 1.56 & 0.08 & 0.34 & 0.21 & 0.53 & \\
\hline
\end{tabular}

$\mathrm{CD}=$ Critical Difference; $\mathrm{P}=$ Probability; NS= Non-significant

quality, viability, dormancy, germination, use of potting mixture, seed size, genetic quality of seed source, etc. Seed size is one of the parameters that affect the seed germination and seedling quality; however, every nursery should follow seed grading prior to sowing and raising of seedlings. Therefore, it is necessary to classify the seed size for each species for proper grading. Most of the reports show that larger seeds produced maximum germination within a short period along with good quality seedling as compared to those of smaller seeds in different species such as Hardwickia binata (Ponnammal et al., 1993), Pongamia pinnata (Manonmani et al., 1996), Vateria indica (Gunaga et al., 2007), Mammea suriga (Gunaga et. al., 2011), Calophyllum inophyllum (Gunaga, 2011) and some of multipurpose tree species (Negi and Todaria, 1997). These reports are conformity with results of present study where bigger seeds produced more germination, seedling growth and biomass as compared to medium and smaller seeds. This could be due to the presence of higher amount of carbohydrates/ food reserves, moisture and other nutrients in bigger seeds than smaller ones. Such trend is not always true in all species. For instance, Dar et al. (2002) reported that some of the multipurpose tree species of Jammu region resulted in good germination and seedling vigour in smaller seeds than large seeds. However, Rezapour et al. (2013) reported that medium sized seeds produced maximum germination and seedling vigour than smaller and larger seeds in soyabean. Therefore, species wise study is required on seed traits and its influence on seed germi- nation and seedling vigour for proper grading to raise quality seedlings in nursery (Gunaga, 2011). Gunaga et al. (2012) studied the seed source variability in seed traits and seedling attributes in $S$. asoca in the Konkan region, Maharashtra. They found that significant variation in various seed traits like seed length, seed thickness and seed weight among different seed sources was recorded; however, Kesari population had smaller seeds and Dodamarg population recorded bigger seeds. Therefore, information on population variation in seed size and seedling attributes is also important for deciding seed size for grading a seedlot.

\section{Conclusion}

Seedlot collected from Pookeri of Dodamarg showed great variation in seed size and it ranged from 21.83 to $48.58 \mathrm{~cm}$ and maximum seeds belonged to seed length class of $35-45 \mathrm{~cm}$. Further, seed length showed strong positive association with seed weight $(r=0.887)$, seed width ( $\mathrm{r}=0.697)$ and thickness $(\mathrm{r}=0.621)$. Among three seed size classes, seeds which are bigger size gave out higher seed germination $(86.7 \%)$ i.e., almost double the smaller seeds $(45.0 \%)$. Of course, there was no much difference in medium seeds $(83.30 \%)$, which was at par with bigger seeds. Furthermore, seedlings raised from bigger to medium seeds showed superior in terms of seedling growth and biomass than seedlings raised from smaller seeds. Therefore, it is suggested to use medium to large seeds of $S$. asoca (i.e., seed length $>30 \mathrm{~cm}$ ) for production of quality seedlings in large scale. 


\section{REFERENCES}

CSIR (1952). The Wealth of India, Saraca asoca. Vol.III: D.E. CSIR, New Delhi, pp. 234-238.

Dar, F.A., Gera, M. and Gera, N. (2002), Effect of seed grading on germination pattern of some multipurpose tree species of Jammu region. The Ind. For., 128: 509-512.

Gomez, K.A. and Gomez, A.A. (1984). Statistical Procedures for Agricultural Research (2nd $2^{\text {nd }}$ ed.). Published by John Wiley and Sons, New York, pp. 680.

Gunaga, R. P., Hareesh, T.S. and Vasudeva, R. (2007). Effect of fruit size on early seedling vigour and biomass in white dammer (Vateria indica): a vulnerable and economically important tree species of the Western Ghats. J. Non Timber Forest Products, 14: 197-200.

Gunaga, R.P. (2011). Influence of seed size on seed germination and seedling vigour in Calophyllum inophyllum: an important multipurpose tree of coastal region. J. Indi. Soc. Coastal Agril. Res., 29(2): 35-38.

Gunaga, R.P., Doddabasav and Vasudeva, R. (2011). Influence of seed size on germination and seedling growth in Mammea suriga. Karnataka J. Agricultrual Science, 24 (3): 415-416.

Gunaga, R.P., Mayur, M.M., Wanage, S.S., Mirgal, A.B., Patwardhan, A., Rane, A.D., Narkhede, S.S., Bhave, S.G. and Vasudeva, R. (2012). Variability in seed traits and seedlings growth of different populations of Saraca asoca in Konkan region. In: National Conference on Biodiversity assessment, conservation and utilization held at MES Abasaheb Garware College, Pune from $9^{\text {th }}$ to $11^{\text {th }}$ Feb. 2012, Book of Abstract, pp. 42-43.

Haridasan, K., Sharma, A., Buyan, C. R. and Bisht, N. S.
(2003). Medicinal sector in Arunachal Pradesh - on overview. The Indian Forester, 129(1): 37-47.

Manonmani, V., Vanangamudi, K. and Rai, R.S.V. (1996). Effect of seed size on seed germination and vigour in Pongamia pinnata. J. Tropical Forest Science, 9: 1-5.

Middlekoop, T. B. (1985). Evaluation of Asoka Aristha: a drug indigenous to Srilanka. Pharmaceutisch weekblad, 7(6): 283-284.

Negi, A.K. and Todaria, N.P. (1997). Effect of seed size and weight on germination pattern and seedling development of some multipurpose tree species of Garhwal Himalaya. The Indian Forester, 123: 32-36.

Ponnammal, N.R., Arjunan, M.C. and Antony, K.A. (1993). Seedling growth and biomass production in Hardwickia binata Roxb. as affected by seed size. The Indian Forester, 119: 59-62.

Ray, S., Chatterjee, B. P. O. and Ray. S. (1995). Saracin: a lectin from Saraca indica seed integument recognizes complex carbohydrates. Phytochemistry, 40(3): 643-649.

Rezapour, R., H. Kazemiarbat, M. Yarnia and P. Z. Moattar (2013). Effect of seed size on germination and seed vigor of two soybean (Glycin max L.) cultivars. International Research Journal of Applied and Basic Sciences, 4(11): 3396-3401.

Ved, D.K. and G.S. Goraya (2007). Demand and Supply of Medicinal Plants in India. NMPB, New Delhi \& FRLHT, Bangalore, India.

Walad, B. (2008). Distribution, Population Structure and Regeneration Status of Remnant Populations of Saraca asoca (Roxb.) De Wilde in the Central Western Ghats. In: National workshop on "Forest, Medicinal Plants and People" held at the College of Forestry, Sirsi. p. 75. 